\title{
LA APROBACIÓN DEL INGRESO MÍNIMO VITAL EN ESPAÑA: UN MODELO PARA SU EVENTUAL IMPLEMENTAGIÓN EN MÉXICO*
}

\author{
THE APPROVAL OF THE MINIMUM VITAL INCOME IN SPAIN: \\ A MODEL FOR ITS EVENTUAL IMPLEMENTATION IN MEXICO
}

\author{
Pablo LATORRE RODRÍGUEZ** \\ Moisés SOTELO SÁNCHEZ***
}

RESUMEN: La aprobación del ingreso mínimo vital en España por medio del Real Decreto-ley 20/2020, pone de manifiesto la cada vez mayor presencia de este impreciso derecho, el cual vendría a constituir la culminación de los derechos de segunda generación acentuada en su vertiente social. En los últimos años, el derecho al mínimo vital está pasando de ser una reivindicación exigida por determinados colectivos sociales, o una entelequia debatida en los círculos doctrinales, a convertirse en una realidad legal en varios países. Ya en 2017 la UE incentivó su adopción por parte de los Estados miembros como un instrumento para la lucha contra la pobreza, pero no ha sido hasta la crisis social provocada por la pandemia del COVID-19 cuando España ha procedido
ABSTRACT: The approval of the minimum vital income in Spain through Royal Decree-Law 20/2020, highlights the increasing presence of this imprecise right, which would come to constitute the culmination of second generation rights accentuated in its social aspect. In recent years, the right to a vital minimum is going from being a claim demanded by certain social groups, or an entelechy debated in doctrinal circles, to becoming a legal reality in several countries. Already in 2017, the EU encouraged its adoption by the Member States as an instrument to fight poverty, but it was not until the social crisis caused by the COVID-19 pandemic that Spain proceeded to do so. In this work, we will analyze the right in question and its nature, and then carefully study

* Recibido el 5 de julio de 2020; aprobado el 17 de enero de 2021.

** ORCID: 0000-0002-1660-8948. Doctor en Derecho por la Universidad de Zaragoza (España); profesor-investigador en la Facultad de Derecho Mexicali de la Universidad Autónoma de Baja California (México).Correo electrónico: platorre@uabc.edu.mx.

*** ORCID: 0000-0002-1380-3481. Licenciado en Derecho por la Facultad de Derecho Mexicali de la Universidad Autónoma de Baja California (México). Correo electrónico: sotelo.moises@uabc.edu.mx.

Boletín Mexicano de Derecho Comparado, nueva serie, año LIV, núm. 160, enero-abril de 2021, pp. 237-276. 
Esta revista forma parte del acervo de la Biblioteca Jurídica Virtual del Instituto de Investigaciones Jurídicas de la UNAM

A ello. En este trabajo, analizaremos el derecho en cuestión y su naturaleza, para después estudiar con atención la forma en que aquel país lo ha regulado, y finalizar analizando la presencia de éste en nuestro sistema jurídico y su potencial aplicación en México

Palabras clave: ingreso mínimo vital, derecho al mínimo vital, derechos humanos, derechos económicos, sociales, y culturales, España. the way in which that country has regulated it, and finish by analyzing its presence in our legal system and its potential application in Mexico.

Keyzeords: vital mínimum income, vital mínimum right, human rights, economical, social, and cultural rights, Spain.

SUMARIO: I. Introducción. II El ingreso mínimo vital: concepto y naturaleza.

III. El ingreso mínimo vital en España. IV. El DMV en México. V. Conclusión: una apuesta por la implementación del DMV en México. VI. Fuentes.

\section{INTRODUCGIÓN}

El derecho al mínimo vital (en adelante DMV) constituye la quintaesencia de los derechos sociales. Su regulación por parte de los países que la han abordado ha venido a aportar una mayor concreción en un derecho, ya de por sí, debatido y difuso. El reconocimiento e implementación de este derecho supone un salto cualitativo enorme en lo que a protección de los derechos humanos se refiere. Comprender sus dimensiones, tanto en el plano doctrinal como en el de la normatividad internacional, es primordial para garantizarlo eficazmente. Por ello, en este trabajo atenderemos a la idea detrás del derecho, a la filosofía que lo inspira, para aproximarnos a un mejor entendimiento de éste que nos permita plantear su adopción en nuestro país como una herramienta de combate contra las desigualdades.

Una sociedad en la que se reconoce y aplica el DMV es una sociedad más justa y respetuosa con los derechos humanos. Debemos continuar trabajando en este sentido para conseguir que la sociedad mexicana se acerque cada día más a los más altos estándares de calidad en la defensa y protección de los derechos humanos, y es allí donde Europa se erige como una referencia indiscutible. Su reciente legislación en España nos brinda la oportunidad perfecta para realizar un estudio comparado

Esta obra está bajo una Licencia Creative Commons

Atribución-NoComercial-SinDerivar 4.0 Internacional, IIJ-UNAM.

Boletín Mexicano de Derecho Comparado, núm. 160, enero-abril de 2021, pp. 237-276. 
Esta revista forma parte del acervo de la Biblioteca Jurídica Virtual del Instituto de Investigaciones Jurídicas de la UNAM

con este país con el cual nos unen tantas similitudes, y por este motivo proponerlo como un modelo para una eventual regulación mexicana. Nuestro objetivo en este artículo es presentar esta herramienta jurídica, para después mediante un análisis de la reciente regulación española, y previo examen de la situación mexicana al respecto, plantear la siguiente hipótesis: la adopción por parte de México del ingreso mínimo vital (IMV) con una regulación semejante a la española (pero adaptada) supondría un avance incuestionable en la garantía y promoción de los derechos humanos en nuestro país. Esta es la idea central defendida en este trabajo.

\section{EL DMV: RECONOCIMIENTO Y MATERIALIZACIÓN}

\section{Concepto y naturaleza del DMV}

El DMV se conceptualiza como la culminación de los derechos de segunda generación (económicos, sociales y culturales), subrayando ante todo la vertiente social. Encuentra pues natural anclaje normativo ${ }^{1}$ en normas internacionales como la Declaración Universal de los Derechos Humanos de 1948, que ya desde su preámbulo hace mención al compromiso de "promover el progreso social y a elevar el nivel de vida", y más específicamente en su artículo 22 establece el derecho a "la satisfacción de los derechos económicos, sociales y culturales, indispensables a su dignidad y al libre desarrollo de su personalidad", viéndose esto reforzado cuando en el numeral 25.1 se declara que "toda persona tiene derecho a un nivel de vida adecuado" concretado en salud, bienestar, alimentación, vestido, vivienda, asistencia médica y servicios sociales necesarios, seguros de desempleo, enfermedad, invalidez, viudez, vejez u "otros casos de pérdida de sus medios de subsistencia por circunstancias independientes de su voluntad".

1 E. Carmona Cuenca en su obra El derecho a un mínimo vital con especial referencia a la Constitución Española de 1978 vincula como antecedente más antiguo al DMV en el ámbito jurídico la frumentatio romana, consistente en un mínimo de trigo para los ciudadanos, ya que se trataba de un derecho autentico y no un simple acto de generosidad. De igual forma dentro del derecho romano se encuentran otras figuras jurídicas con características y objetivos similares, tales como la liberalitas o congiaria, cuya característica principal consistía en entregar prestaciones en dinero o alimentos.

Esta obra está bajo una Licencia Creative Commons Atribución-NoComercial-SinDerivar 4.0 Internacional, IIJ-UNAM. Boletín Mexicano de Derecho Comparado, núm. 160, enero-abril de 2021, pp. 237-276. 
Esta revista forma parte del acervo de la Biblioteca Jurídica Virtual del Instituto de Investigaciones Jurídicas de la UNAM

Más enfático resulta el Pacto Internacional de Derechos Económicos, Sociales y Culturales de 1966 el cual también incluye el derecho a un nivel de vida adecuado en su artículo 11 agregando el derecho a "una mejora continua de las condiciones de existencia", lo que aporta un carácter dinámico al mismo, y contribuyendo a una mayor concreción en su artículo 12 .

Además de estos documentos jurídicos de carácter internacional, el DMV también hunde sus raíces en otros como la Declaración sobre el Progreso y el Desarrollo en lo Social, de 1969, o la Declaración Universal sobre la Erradicación del Hambre y la Malnutrición, de 1974. A escala regional, la Convención Americana de los Derechos Humanos, de 1969, y el Protocolo de San Salvador, de 1988, que enumera en mayor detalle los derechos sociales y manifiesta su interdependencia indisoluble con otros derechos humanos, son normas fundamentales en este sentido.

En el ámbito europeo sobresalen la Carta Social Europea, la Carta de Derechos Fundamentales de la Unión Europea y su Tratado de Funcionamiento. El Parlamento Europeo emitió, en 2017, una resolución sobre la "Renta mínima como instrumento para la lucha contra la pobreza", 2 donde recomendó a los Estados miembros la introducción de

regímenes de renta mínima adecuados, acompañados de medidas para favorecer la reincorporación al mercado de trabajo de todas las personas capaces de trabajar y de programas de educación y formación adaptados a la situación personal y familiar del beneficiario, con el fin de ayudar a las familias con ingresos insuficientes y permitirles que tengan un nivel de vida digno.

En puridad, no existe un concepto unívoco de "mínimo vital" (S. P. Duque, M. Duque Quintero y P. González Sánchez, 2019, pp. 80-95). En la doctrina, encontramos voces que, como Ferrajoli, entienden que el mínimo vital sería un componente del propio derecho a la vida (L. Ferrajoli, 2011, p. 18), hasta quien como Rawls lo ven como un mecanismo de igualdad social (J. Rawls, 1971). En este sentido el verdadero problema que afecta al DMV ha sido su falta de concreción, y, por tanto (derivada de ella) su materialización, su exigibilidad ante las instancias judiciales

2 Resolución del Parlamento Europeo, del 24 de octubre de 2017, sobre las políticas encaminadas a garantizar la renta mínima como instrumento para luchar contra la pobreza.

Esta obra está bajo una Licencia Creative Commons

Atribución-NoComercial-SinDerivar 4.0 Internacional, IIJ-UNAM.

Boletín Mexicano de Derecho Comparado, núm. 160, enero-abril de 2021, pp. 237-276. 
Esta revista forma parte del acervo de la Biblioteca Jurídica Virtual del Instituto de Investigaciones Jurídicas de la UNAM

y su justiciabilidad. ${ }^{3}$ ¿Qué es entonces el DMV? La clave está en definir si se trata de un derecho en exclusiva, con un reconocimiento específico, o si es un referente innominado que a modo de cajón de sastre da cabida a lo que diferentes voces e interpretaciones entienden como "mínimo", y dónde entrarían desde la vivienda y alimentación, hasta la salud, la educación y el medio ambiente.

Como expone Espinoza de los Monteros, los derechos sociales se caracterizan por contener un conjunto de expectativas, pretensiones de derechos, recursos y bienes, que albergan la finalidad de satisfacer "necesidades materiales mínimas" (J. Espinoza de los Monteros, 2013, p. 376). El DMV surge con la vocación de ser el agente que satisfaga estas necesidades materiales mínimas o indispensables, mediante la transformación aquellas expectativas y pretensiones ideales en realidades materiales y palpables.

En cuanto a su exigibilidad y justiciabilidad ${ }^{4}$ entendemos el mínimo vital como un parámetro para hacer exigible los derechos económicos, sociales y culturales, no solamente ante los tribunales sino también frente a las administraciones públicas. Como expresa E. Pérez González,

En el sistema jurídico mexicano, el DMV impone, en el marco de las obligaciones de actuación encomendadas a las administraciones públicas, los deberes de promoción, fomento, protección y garantía de los derechos humanos. De este modo, el DMV proporciona un parámetro de exigibilidad frente a la omisión de deberes de actuación administrativa" (E. Pérez González y A. Nettel Barrera, 2017, pp. 317-337).

Ahora bien, acordamos con Carlos Pelayo, que la justiciablidad del mínimo vital pasa por la garantía judicial de este derecho de manera individualizada:

3 Como señala Rosales García, el DMV no sólo busca garantizarle al individuo percibir ciertos recursos, sino permitirle desarrollar un proyecto de vida igual que al común de la sociedad. De allí que también sea una medida de justicia social, propia de un Estado constitucional. (C. M. Rosales García, 2016, p. 115)

4 "La justiciabilidad tiene que ver con el reconocimiento que una sociedad haga de un derecho y con su cumplimiento voluntario; la exigibilidad se relaciona con la posibilidad de hacer compulsivo el cumplimiento o la reparación de un derecho que se ha violentado. Buena parte de la doctrina entiende justiciabilidad con el significado, muy estrecho, de hacer valer un derecho ante los tribunales". 
Esta revista forma parte del acervo de la Biblioteca Jurídica Virtual del Instituto de Investigaciones Jurídicas de la UNAM

Una forma de resolver preliminarmente estas dificultades y dar pasos firmes hacia la justiciabilidad de los derechos económicos, sociales y culturales es garantizar, vía judicial, el derecho a un "mínimo vital", es decir, a las condiciones mínimas para que una persona tenga acceso a una vida digna. (C. Pelayo Möller, 2012).

Concluimos así que la exigibilidad del DMV es un camino para hacer efectiva la reclamación de otros derechos humanos de segunda generación, y por consiguiente entendemos prioritaria su regulación normativa, tarea para la cual podemos encontrar inspiración en el modo en que España lo ha ejecutado por medio del IMV, esto es una prestación dirigida a prevenir el riesgo de pobreza y exclusión social mediante la transferencia de recursos económicos suficientes para la cobertura de sus necesidades básicas.

\section{El DMV el IMV,y otros conceptos análogos}

En ocasiones el concepto "mínimo vital" (común al DMV y al IMV) puede ser denominado "mínimo existencial" o "mínimo de subsistencia", utilizándose a menudo estas nomenclaturas como sinónimos. De igual forma, en la doctrina del liberalismo social se utiliza el concepto de "mínimo social", y en algunos casos se le equipara con el concepto de "renta básica universal" o el "salario social básico". Si bien es cierto, dentro del ámbito jurídico suele usarse el concepto de mínimo vital para referirse a diversas cuestiones, todas ellas se relacionan de forma evidente con la protección de las necesidades básicas más fundamentales para el ser humano.

En Latinoamérica no somos ajenos a esta heterogeneidad como comprueba L. A. Petit en su estudio (L. A. Petit, 2019). E. Carmona Cuenca define el derecho a un mínimo vital como el "derecho de todos los individuos que forman una comunidad a contar con una cantidad mínima para hacer frente a sus necesidades más básicas" (E. Carmona Cuenca, 2012, pp. 61-85). En este sentido abunda Indacochea Prevost señala que el DMV "vendría a ser aquel derecho de todo individuo (...) a contar con la cantidad mínima de recursos que le permitan hacer frente a sus necesidades más básicas". La autora acude al profesor Jimena Quesada para afirmar que puede definirse como un "derecho a recursos mínimos 
Esta revista forma parte del acervo de la Biblioteca Jurídica Virtual del Instituto de Investigaciones Jurídicas de la UNAM

garantizados". Finalmente concluye que el contenido que debe otorgarse al mínimo vital depende de lo que resulte necesario en el caso concreto. Por lo que considera suficiente que se defina de manera general "como un derecho a contar con los recursos mínimos para asegurar la subsistencia de cada individuo" (Ú. Indacochea Prevost, 2011, pp. 259, 265, 266 y 283). Por su parte Silva Meza, en la línea ferrajoliana antes señalada, subraya la estrecha relación que guarda el DMV con el derecho a la vida (J. Silva Meza, 2014, pp. 213-240).

Carmona Cuenca en su artículo "El derecho al mínimo vital y el derecho a la renta básica", también comenta la postura de Jimena Quesada, relativa a los recursos mínimos garantizados, considerando que la amplitud del concepto que ofrece éste (la cual engloba los derechos de vivienda, salud, alimentación y educación, que deben ser cubiertos mediante servicios públicos para aquellos que no están en condiciones de proveerse de ellos por sí mismos) le restaría precisión y por tanto eficacia, y que el DMV debería ser tratado como un derecho en específico (E. Carmona Cuenca, 2017, pp. 199-209).

En este sentido sostiene que el mínimo vital "se refiere más bien a la libre disposición de recursos económicos mínimos para hacer frente a las necesidades más perentorias del ser humano" 5 y explica su postura exponiendo que el DMV en principio podría entenderse bien como una disposición a favor de los trabajadores para que el salario que perciben sea suficiente, o bien en pro de las personas que por alguna circunstancia no realizan un trabajo remunerado, inclinándose en favor del segundo supuesto, basando su postura en que los trabajadores ya cuentan con una serie de disposiciones en el marco internacional que protege su salario, y según la autora, el mínimo vital tiene otro objetivo: dar respuesta a las personas que no tienen un trabajo remunerado ni disponen de bienes económicos propios y suficientes.

Se podría concluir entonces que el mínimo vital, como derecho de satisfacción de necesidades básicas, debe tutelar a quienes están más apartados de tener un nivel de vida adecuado. Aun así, la autora no niega dicha relación, incluso sostiene que en países en vía de desarrollo los trabajadores no cuentan con los medios de subsistencia, y en países desarrollados sus salarios son para la mera subsistencia o insuficientes. Por lo que el

5 Ibidem, p. 201. 
Esta revista forma parte del acervo de la Biblioteca Jurídica Virtual del Instituto de Investigaciones Jurídicas de la UNAM

mínimo esencial puede tomarse como punto de partida y solamente considera conveniente enfocarlo en los que se encuentran en mayor desventaja. En este orden de ideas el DMV persigue el alcance efectivo de los derechos desde un aspecto material que pretende trascender el universo de la idealidad en el que se sitúan muchos derechos reconocidos en el plano normativo, los cuales no consiguen una materialización real de los mismos comúnmente debido a la falta de medios para hacerlos posibles. El DMV viene a proveer de esos medios necesarios para asegurar el resto de los derechos sociales garantizados y para asegurar que devengan efectivamente una realidad palpable.

Por consiguiente, si el DMV es la institución jurídica que protege esta potestad del individuo, el IMV vendría a ser la herramienta a través de la cual aquel toma forma vigente, la política pública que lo hace tangible, sin embargo, los conceptos de DMV y su materialización en IMV han sido, y son hoy en día, intensamente debatidos en cuanto a su concreción y alcance. Tanto la doctrina como el regulador jurídico abordan el DMV desde diversos ángulos y poniendo el foco en los diferentes aspectos que éste abarca, pero prácticamente todos coinciden en su configuración como el nivel más avanzado al cual los derechos humanos de segunda generación han llegado, encarnando el DMV la sublimación de todos ellos y de su correlativa garantía.

La cuestión respecto a la cual discurre el debate en torno al DMV es su alcance. Aquí es dónde el DMV y su concreción como IMV necesitan una mayor precisión en cuanto a la vinculación que mantienen entre ellos y con otros conceptos relacionados.

En primer lugar, debemos distinguir el IMV de la renta básica universal (RBU). Acudamos a la definición que el profesor belga Van Parijs (uno de los expertos más reconocidos en la materia $)^{6}$ hace de la misma:

[la RBU consiste en] un ingreso pagado por el gobierno a cada miembro pleno de la sociedad, incluso si no quiere trabajar de forma remunerada, sin tomar en consideración si es rico o pobre o, dicho de otra forma, independientemente de sus otras posibles fuentes de renta y sin importar con quién conviva. (P. Van Parijs, 1996, p. 56)

6 Fundamental en este sentido resulta: (P. Van Parijs, 2001 pp. 7-39).

Esta obra está bajo una Licencia Creative Commons

Atribución-NoComercial-SinDerivar 4.0 Internacional, IIJ-UNAM.

Boletin Mexicano de Derecho Comparado, núm. 160, enero-abril de 2021, pp. 237-276. 
Esta revista forma parte del acervo de la Biblioteca Jurídica Virtual del Instituto de Investigaciones Jurídicas de la UNAM

El IMV se dirige a los desprotegidos o aquellos con mayores dificultades para acceder a las necesidades básicas, mientras que la RBU es independiente a la situación económica de la persona. La RBU consiste en conceder una cantidad en dinero a todas las personas sin importar su situación laboral, social o económica, por lo que se también sería reclamable por personas sin dificultades económicas o con un alto nivel de ingresos. Es decir, el IMV no se dirige a todos los ciudadanos, sino que se destina para aquellos en una determinada situación de vulnerabilidad económica, debiendo acreditar además determinados requisitos, y la renta básica ciudadana (también llamada así en ocasiones) es, efectivamente, universal desde su raíz (C. Gala Durán, 2020). Las diferencias entre uno y otro concepto aparecen perfectamente esquematizadas en esta cita de Rey Pérez:

$\mathrm{La}(\ldots) \mathrm{RBU}$, se caracteriza por ser un ingreso individual, periódico, incondicional y universal, mientras que el (...) ingreso mínimo vital (como ha aprobado recientemente el Gobierno español), son ingresos familiares, periódicos, condicionados y no universales, pues se dirigen solo a aquellos colectivos que tienen necesidad de una ayuda económica para cubrir sus necesidades de subsistencia. (J. L. Rey Pérez, 2020, p. 238)

Con este contraste entre ambos conceptos observamos que difieren no sólo en su objeto y su objetivo, sino también en su propio diseño y por supuesto en su coste a las arcas públicas. El IMV y la RBU no buscan el mismo fin. Un instrumento incondicionado como la RBU, con esa vocación universal ciega a las diferencias resulta inevitable encuadrarlo en una concepción liberal basada en la neutralidad estatal más que en un verdadero Estado social. ${ }^{7}$ Esta discusión walzeriana (M. Walzer, 1991) sobre

7 "Walzer considera que las dos perspectivas universalistas definen dos concepciones diversas del liberalismo, la segunda más democrática que la primera. Lo que Walzer llama "liberalismo 2", en la medida en que autoriza a las comunidades democráticas a determinar la política pública dentro de los vastos límites del respeto a los derechos individuales, también las autoriza a elegir las medidas políticas que resulten más o menos neutrales entre las particulares identidades culturales de los grupos. Y dado que el liberalismo 2 es democrático, puede escoger al liberalismo 1, la neutralidad estatal, por medio de un consenso democrático. Walzer cree que esto es lo que Estados Unidos ha escogido democráticamente. Y el Liberalismo 1 que se incluye en la elección del liberalismo 2 es lo que Walzer habría elegido, porque está en armonía con la interpretación social dominante de 
Esta revista forma parte del acervo de la Biblioteca Jurídica Virtual del Instituto de Investigaciones Jurídicas de la UNAM

la naturaleza del Estado benefactor es para nosotros la verdadera clave de la opción entre un modelo u otro. Además de la obvia disparidad económica entre las dos (no asumible por muchos Estados), este desfase en su alcance subjetivo es la esencia de la elección que nos hace posicionarnos en favor del IMV en detrimento de la RBU. Si la RBU es una renta igual para todos no cuenta con un factor igualador, no existe una verdadera redistribución, no nivela, ni mitiga la desigualdad. No negamos un efecto estimulante para la economía a corto plazo, pero enseguida quedará diluido, y a medio-largo plazo acaba perpetuando las condiciones originales que pretendía evitar.

La RBU no desarrolla el DMV. La RBU es un mecanismo igualitarista de redistribución de la renta que no atiende desde su concepción intrínseca a la misma finalidad que el DMV. No podemos caer en la trampa de presentar ambos como mecanismos mediante los cuales un sistema jurídico puede hacer efectiva la protección del DMV. La única vía de implementar el DMV es el IMV.

En otro orden de cosas, también debemos distinguir el IMV de otros conceptos relacionados como el "salario social básico" o la "renta mínima de inserción". Todos ellos tienen como finalidad proteger a las personas contra el desempleo y reincorporarlos a la vida económica por medio de prestaciones económicas, a fin de que puedan satisfacer sus necesidades más básicas. La diferencia con la RBU estriba en que van encaminados a personas en situación de desventaja social, en especial ciudadanos o personas con cierto tiempo de residencia que buscan reinsertarse a la vida económica de la sociedad. La similitud con el mínimo vital reside en que ambos pretenden asegurar que las personas que lo necesiten cuenten con los medios suficientes para satisfacer sus necesidades y puedan reincorporarse a la sociedad de manera productiva, sin embargo, existen discrepancias en cuanto al alcance, duración y beneficiarios de la acción protectora.

Estas figuras jurídicas también guardan similitud, con el concepto de mínimo social descrito por Rawls en su obra Teoría de la justicia, y anteriormente señalado, el cual propone un nivel de recursos mínimos que de-

Estados Unidos como una sociedad de inmigrantes, en que cada grupo cultural es libre de defenderse a sí mismo, si bien no cuenta con el Estado para el apoyo o reconocimiento de sus proyectos culturales". (A. Guttman, 2003, pp. 9 y 10)

Esta obra está bajo una Licencia Creative Commons

Atribución-NoComercial-SinDerivar 4.0 Internacional, IIJ-UNAM.

Boletin Mexicano de Derecho Comparado, núm. 160, enero-abril de 2021, pp. 237-276. 
Esta revista forma parte del acervo de la Biblioteca Jurídica Virtual del Instituto de Investigaciones Jurídicas de la UNAM

ben ser cubiertos por el Estado a favor de aquellos que lo requieran, como medio para cumplir el objetivo del pleno desarrollo de la persona en la sociedad (J. Rawls, 1971).

También aquí aparece la conexión del DMV con la inembargabilidad de los recursos y bienes materiales vitales, que establece limitantes a ciertos derechos con el objeto de proteger a la persona humana. Al mínimo vital suele denominársele mínimo inembargable o exento, por constituir una restricción en favor de proteger el patrimonio de los individuos. El punto central es proteger a los individuos de caer en una situación de insubsistencia y vulnerabilidad por cuestiones económicas.

Observamos pues como el DMV mantiene un claro nexo con conceptos como renta básica universal o rentas mínimas de inserción, sin embargo, el DMV no tiene el grado de concreción del que disfrutan los otros conceptos. ${ }^{8}$ Pese a que nosotros nos alineamos con aquella parte de la doctrina que destaca la necesidad de especificidad del mínimo vital como un derecho propio e individualizado, otra parte entiende que del concepto general del mínimo existencial no se desprende la obligación indiscutible de incorporar dentro del marco normativo estas prestaciones. El mínimo vital desde su teoría si implica ciertas obligaciones y libertades en favor del gobernado por parte de los poderes públicos, pero estas pueden consistir únicamente en la prestación de servicios como por ejemplo salud, o el acceso al agua, pero no explícitamente en el otorgamiento de seguros o prestaciones monetarias en forma de transferencia económica directa desde el Estado a los individuos. En otras palabras: no hay unanimidad doctrinal en cuanto a que el DMV deba garantizar inevitablemente el IMV.

El DMV es un concepto más abstracto que instituye la obligación del Estado de garantizar las necesidades fundamentales para la subsistencia, pero sin constreñirse o limitarse a actividades específicas. Sin embargo, que se trate de un concepto amplio no quiere decir que no se puedan exigir o demandar medidas determinadas para concretar los fines perseguidos por el mínimo vital. En definitiva, se trata de un derecho humano con un alto grado de inconcreción, lo que por otro lado estimula su flexibilidad y adaptabilidad.

8 Y por supuesto no podemos confundir el mínimo vital con dádivas y demás subvenciones políticas comunes en nuestro país (L. A. Petit, 2019). 
Esta revista forma parte del acervo de la Biblioteca Jurídica Virtual del Instituto de Investigaciones Jurídicas de la UNAM

\section{EL INGRESO MÍNIMO VITAL EN ESPAÑA}

La causa fundamental que motiva la elaboración de este trabajo es la aprobación del Real Decreto-ley 20/2020, del 29 de mayo, que es la norma española que instituye el IMV, y que será la norma de referencia para la primera parte de nuestro estudio comparado. La elección del caso español como referencia para el estudio de una potencial aplicación en México no es baladí. Ambas sociedades comparten importantes rasgos que hacen que las recetas aplicadas en una puedan tener éxito también en su aplicación en la otra. Los lazos históricos y culturales comunes entre España y México, fruto de un pasado común y de una comunicación y vínculos firmes, explican que la percepción social de determinados valores como la solidaridad, o el concepto de familia, sean similares y desde luego mucho más cercanos entre ellos que respecto a los países anglosajones o nórdicos. Y lo mismo sucede en los aspectos negativos: los países latino-mediterráneos tenemos una estructura político-institucional más frágil y unos aparatos públicos asistenciales más débiles y peor dotados que implican, por lo general, una mayor vulnerabilidad social, haciendo que en estos países la red de protección social no provenga de los poderes públicos, sino de las familias. En definitiva, para México, no es tan fácilmente extrapolable una solución escandinava o anglosajona, como una española. Con España existe un lenguaje común (no sólo idiomático, sino sociológico) que facilita la comprensión, y además sirve de puente entre Europa y América Latina. En lo jurídico formamos parte de la misma familia y tradicionalmente España ha suministrado una puerta de entrada a las novedades del viejo continente. Por todo ello planteamos que puede ser una buena referencia para la regulación en México del derecho que nos ocupa y de las políticas públicas que lo materializan.

Previamente a la aprobación del citado Real Decreto-ley, en España ya existía una regulación de esta herramienta jurídica. Pero limitada únicamente en el ámbito autonómico (estatal en el estándar mexicano), y adoptando modelos muy diferentes entre sí, tanto en su diseño y denominación como en los grados de protección. Esta heterogeneidad hacía necesaria una uniformización en aras de la igualdad y del alcance de la cobertura social. Ya hemos hablado de la resolución de 2017 del Parlamento Europeo sobre la renta mínima, pero es que en el mismo año se 
Esta revista forma parte del acervo de la Biblioteca Jurídica Virtual del Instituto de Investigaciones Jurídicas de la UNAM

instituyó en la Cumbre social en favor del empleo justo y el crecimiento, el Pilar Europeo de Derechos Sociales, cuyo principio 14 está consagrado a este propósito. ${ }^{9}$

En su preámbulo, el Real Decreto-ley 20/2020 expone que España se encuentra entre los países de la Unión Europea con mayor desigualdad en la distribución de la renta, y con una de las tasas de pobreza más altas, ${ }^{10}$ debido, entre otras causas, al débil efecto redistributivo del conjunto de la intervención de los poderes públicos, y a que este país no cuenta con una prestación que cubra el riesgo general de pobreza como si hacen la mayoría de sus vecinos.

Por si todo esto fuese poco, en los primeros meses de 2020 la pandemia causada por el COVID-19 impactó fuertemente en España, convirtiéndolo en uno de los países más golpeados mundialmente. La crisis no fue únicamente de índole sanitaria, sino que tuvo su traslación en una grave crisis social y económica que provocó un enorme efecto negativo en la actividad laboral y la destrucción de buena parte del tejido productivo. Ante esta situación, el gobierno decidió acelerar la puesta en marcha de esta medida que ya llevaba tiempo incubándose. ${ }^{11}$ Sin embargo, aunque el establecimiento del IMV se haya visto anticipado de manera urgente como una fórmula para mitigar las profundas consecuencias de esta coyuntura, tiene una nítida vocación estructural.

9 Principio 14 del Pilar Europeo de Derechos Sociales, Cumbre social en favor del empleo justo y el crecimiento, Gotemburgo, noviembre de 2017: "Toda persona que carezca de recursos suficientes tiene derecho a unas prestaciones de renta mínima adecuadas que garanticen una vida digna a lo largo de todas las etapas de la vida, así como el acceso a bienes y servicios de capacitación. Para las personas que pueden trabajar, las prestaciones de renta mínima deben combinarse con incentivos a la (re)integración en el mercado laboral".

10 En 2018, el último año para el que Eurostat ofrece datos comparados, el coeficiente de Gini en España es casi tres puntos superior a la media de la Unión Europea, y los ingresos del veinte por ciento de los hogares de renta más baja representan solo una sexta parte de los ingresos del veinte por ciento con renta más alta, mientras en la Unión Europea esta proporción es solo de una quinta parte.

11 En febrero de 2017, el Parlamento español tomó en consideración una Iniciativa Legislativa Popular, a propuesta de los dos sindicatos más importantes del país, con el objetivo de establecer una prestación de ingresos mínimos. Se trata de la primera propuesta relevante en este ámbito, que, sin duda, supuso un fuerte impulso para el desarrollo del ingreso mínimo vital. 
Esta revista forma parte del acervo de la Biblioteca Jurídica Virtual del Instituto de Investigaciones Jurídicas de la UNAM

Respecto al debate sobre la aprobación de esta medida en España podemos establecer dos ámbitos, siendo el primero de ellos el doctrinal y, el segundo, el político-parlamentario. En ninguno de ellos han surgido polémicas o discusiones reseñables. En 2015 los principales sindicatos españoles (CCOO y UGT) comenzaron una campaña de recogida de firmas para llevar a cabo una iniciativa legislativa popular sobre una renta mínima para aquellos sin ingresos y sin derecho a prestaciones por desempleo u otras ayudas sociales. Se ponía de esta manera encima de la mesa la cuestión que ya había sido implementada en varios países del entorno español, y que estaba siendo demandada desde las instancias europeas ${ }^{12}$ ya que suponía una anomalía entre las economías más potentes de la Unión Europea. ${ }^{13}$ En este sentido, y como corresponde a su función de vanguardia, la doctrina ha venido estudiando concienzudamente el asunto y dilucidando cuál sería el instrumento más idóneo para la realidad española (F. Goerlich Gisbert, 2016).

Los partidarios de la RBU añaden a los argumentos ya analizados anteriormente como ventaja frente al IMV la no estigmatización de los receptores (T. Sala Franco y A. Martín Pozuelo, 2020, p 73 y M. Ramos Quintana, 2020, p. 303). Bajo nuestro criterio, la opción de un instrumento incondicional y absoluto no encontraría un problema en este punto (consideramos más grave la estigmatización causada por la pobreza), y si más bien en el temor manifestado por algunos respecto a las consecuencias desincentivadoras que pueda causar una medida de este tipo en los receptores de ésta como presagian desde determinados espectros políticos liberales (J. L. Monereo Pérez y G. Rodríguez Iniesta, 2020, p. 24). Temor que una herramienta condicionada y no-universal como el IMV, ostenta el mérito de alejar, e incluso servir como incentivo al empleo en el difícil contexto actual, tal como muestra L. Martínez Virto (2019).

El mayor o menor éxito de experiencias de RBU ya ensayadas en lugares como Finlandia (analizado magistralmente por P. Van Parijs 2020)

12 Recomendación del Consejo relativa al Programa Nacional de Reformas de 2020 de España y por la que se emite un dictamen del Consejo sobre el Programa de Estabilidad de 2020 de España.

1315 de los 27 Estados miembros de la Unión Europea cuentan con un instrumento similar que garantiza al menos un ingreso mínimo de 200 euros mensuales, siendo Dinamarca y los Países Bajos los que proporcionan cifras más altas: 1.515 y 992 euros respectivamente. 
Esta revista forma parte del acervo de la Biblioteca Jurídica Virtual del Instituto de Investigaciones Jurídicas de la UNAM

o Alaska ${ }^{14}$ no son trasladables directamente a España. No dudamos de sus buenos resultados, pero circunscritos a sus contextos específicos (Finlandia es uno de los mejores ejemplos de socialdemocracia escandinava con una consolidada tradición basada en una verdadera redistribución de la renta, poderes públicos capaces y eficientes, y sistemas asistenciales fuertes, mientras que Alaska basa su éxito en los enormes ingresos procedentes de sus recursos petrolíferos), contextos de los que España (al igual que México) carece. Todos estos factores hicieron que la opción del gobierno español por el IMV fuese mayoritariamente bienvenida por la doctrina. Añadiendo a esto la situación de precariedad económica y vulnerabilidad social provocada por la crisis pandémica, se generó la oportunidad perfecta para que el gobierno llevase a cabo una de sus medidas estrella contenida en el acuerdo de coalición. ${ }^{15} \mathrm{El}$ gobierno ya planeaba, por tanto, la aprobación de la medida a lo largo de la legislatura, pero la emergencia social a que aludimos urgió su aprobación.

14 Merece la pena contemplar un momento la experiencia particular alasqueña descrita magistralmente por Tena Camporesi en los siguientes términos: "Desde el año 1982 lleva activo en Alaska el Permanent Found Dividend, la única "verdadera" experiencia en la práctica de RBU llevada a cabo en un territorio, no de manera experimental, sino como derecho subjetivo ciudadano y de forma continuada en el tiempo. Desde entonces cada año una parte de los ingresos que genera el petróleo que se extrae en esa zona se ingresa en este fondo. La idea era transformar de manera permanente los ingresos derivados del petróleo en un flujo de dinero y capital hacia los residentes en Alaska. Las únicas condiciones para poder optar a este dividendo son la ciudadanía, la residencia y rellenar un formulario. El Alaska Permanent Found es el único caso existente hoy en día de una RBU individual universal e incondicional explícitamente como política de Estado. Los dividendos se pagan de manera anual y aunque son variables en función del precio del petróleo en el mercado, los promedios que se calculan van en torno a los 1.200 dólares al año, es decir, para una familia de cinco personas unos 6000 dólares (Widerquist y Sheahen, 2012). Ahora mismo Alaska es el estado más igualitario de los Estados Unidos en cuanto a distribución de la renta, con un índice de Gini del 0.408 con respecto al 0.481 de media del país, y el más alto del país es el del Distrito de Columbia con un 0.54 (Noss, 2014). El problema más obvio en términos de sostenibilidad sigue siendo su relación directa con un recurso determinado: el petróleo, que se calcula que pueda empezar a terminarse entre 15 y 30 años, lo cual pondría obviamente en peligro el sistema (Widerquist, 2012). Hoy el Permanent Found es un fondo fideicomiso que gestiona la Alaska Permanent Found Corporation, que es propiedad del estado de Alaska, y opera con el 15\% del dinero que se genera de la explotación del petróleo de la región". (A. Tena Camporesi, 2018, pp. 859 y 860)

15 El gobierno español surgido de las elecciones generales de noviembre de 2019 que conformaron las Cortes Generales de la XIV legislatura es el primer gobierno de coalición español a nivel estatal desde la II República en los años treinta del siglo XX. 
Esta revista forma parte del acervo de la Biblioteca Jurídica Virtual del Instituto de Investigaciones Jurídicas de la UNAM

En definitiva, tampoco existió controversia parlamentaria al respecto. La medida fue votada en favor por todos los grupos parlamentarios salvo uno que se abstuvo. ${ }^{16}$ Semejante concordia se explica por dos motivos: en primer lugar, la urgente necesidad que de esta medida reclamaban amplios sectores de la sociedad española (sumados a las presiones europeas e incluso de la ONU); ${ }^{17}$ y, en segundo lugar, las especiales y difíciles circunstancias en que se aprobó. Bien es cierto que el Real Decreto-ley, será tramitado como proyecto de ley y puede ser debatido y modificado en fase de enmiendas, pero todo hace indicar que, salvo breves concesiones, ${ }^{18}$ el diseño del gobierno saldrá adelante.

Entrando ya en el análisis de la regulación del IMV en España, observamos cómo el objetivo es "garantizar, por medio de la satisfacción de unas condiciones materiales mínimas, la participación plena de toda la ciudadanía en la vida social y económica, rompiendo el vínculo entre ausencia estructural de recursos y falta de acceso a oportunidades en los ámbitos laboral, educativo, o social de los individuos. La prestación no es por tanto un fin en sí misma, sino una herramienta para facilitar la transición de los individuos desde la exclusión social que les impone la ausencia de recursos hacia una situación en la que se puedan desarrollar con plenitud en la sociedad". ${ }^{19}$ Del mismo modo, se aclara que el IMV "no es una política dirigida a grupos o individuos concretos, sino que, atendiendo a aquellos que en un momento determinado sufren situaciones de exclusión y vulnerabilidad, protege de forma estructural a la sociedad en su conjunto". ${ }^{20}$

Respecto a su anclaje constitucional, el IMV encuentra fundamento en el reconocimiento del carácter social del Estado español que promul-

\footnotetext{
16 El grupo parlamentario correspondiente al partido ultraderechista Vox se decantó por la abstención.

17 Declaración del relator especial de las Naciones Unidas sobre la extrema pobreza y los derechos humanos, Philip Alston, sobre la conclusión de su visita oficial a España, 27 de enero-7 de febrero de 2020.

18 El Partido Popular (principal grupo de la oposición) pretende que la percepción de la prestación esté vinculada a la "búsqueda activa de empleo".

19 Punto III del Preámbulo del Real Decreto-ley 20/2020, del 29 de mayo, por el que se establece el ingreso mínimo vital, España.

20 Idem.
}

Esta obra está bajo una Licencia Creative Commons

Atribución-NoComercial-SinDerivar 4.0 Internacional, IIJ-UNAM.

Boletin Mexicano de Derecho Comparado, núm. 160, enero-abril de 2021, pp. 237-276. 
Esta revista forma parte del acervo de la Biblioteca Jurídica Virtual del Instituto de Investigaciones Jurídicas de la UNAM

ga el artículo 1.1 de la Constitución Española de 1978; ${ }^{21}$ en el mandato de promoción de la igualdad y remoción de los obstáculos que la dificultan del artículo $9.2,{ }^{22}$ y en el régimen público de seguridad social garantizado por el artículo $41^{23}$ y refrendado como "función de Estado" por el Tribunal Constitucional de aquel país. ${ }^{24}$

Tal y como lo regula el Real Decreto-ley 20/2020, el IMV es una

prestación dirigida a prevenir el riesgo de pobreza y exclusión social de las personas que vivan solas o integradas en una unidad de convivencia, cuando se encuentren en una situación de vulnerabilidad por carecer de recursos económicos suficientes para la cobertura de sus necesidades básicas. (Real Decreto-ley 20/2020, art. 1o.).

De este modo, y como ya indicábamos en el apartado correspondiente, el IMV se configura como el derecho subjetivo a una prestación de naturaleza económica que garantiza un nivel mínimo de renta a quienes se encuentren en situación de vulnerabilidad económica (Real Decreto-ley 20/2020, art. 2.1). El IMV constituye la materialización del DMV, institución jurídica cuyo fin es garantizar una mejora de oportunidades reales de inclusión social y laboral de las personas beneficiarias.

Las características de este instrumento vienen definidas en el artículo 3o. de la citada norma y establecen que se trata de una "acción protectora", cuya duración se prolongará mientras persista la situación de vulnerabilidad económica y se mantengan los requisitos que originaron el derecho a su percepción, que tiene como objetivo garantizar un nivel mínimo de renta que favorezca el tránsito desde una situación de exclusión a una

21 Artículo 1.1. "España se constituye en un Estado social y democrático de Derecho, que propugna como valores superiores de su ordenamiento jurídico la libertad, la justicia, la igualdad y el pluralismo político".

22 Artículo 9.2. "Corresponde a los poderes públicos promover las condiciones para que la libertad y la igualdad del individuo y de los grupos en que se integra sean reales y efectivas; remover los obstáculos que impidan o dificulten su plenitud y facilitar la participación de todos los ciudadanos en la vida política, económica, cultural y social”.

23 Artículo 41. "Los poderes públicos mantendrán un régimen público de Seguridad Social para todos los ciudadanos que garantice la asistencia y prestaciones sociales suficientes ante situaciones de necesidad, especialmente en caso de desempleo. La asistencia y prestaciones complementarias serán libres".

24 Sentencia 37/1994. Tribunal Constitucional de España. 
Esta revista forma parte del acervo de la Biblioteca Jurídica Virtual del Instituto de Investigaciones Jurídicas de la UNAM

de participación en la sociedad, que es intransferible, y que además implica una red de protección que contiene en su diseño incentivos al empleo y a la inclusión, articulados mediante distintas fórmulas de cooperación entre administraciones.

Pero, además, la norma resulta destacable en lo que respecta al alcance de su acción protectora, su ámbito subjetivo de aplicación, y otros aspectos de esta herramienta jurídica, que a continuación pasamos a estudiar.

La cuestión de quién puede ser titular de la materialización en la que se transforma el DMV cuando se plasma como IMV, es una de las claves de la regulación de este derecho. En España el IMV se traduce en una prestación económica recibida por el beneficiario mes a mes (Real Decreto-ley 20/2020, art. 9o.). La determinación de la cuantía de la prestación, y de las personas que la reciben es una de las cuestiones más interesantes que nos aporta la experiencia española, y de la cual podemos extraer importantes lecciones para una potencial aplicación en el ámbito mexicano.

Para el legislador español el IMV es un derecho subjetivo a una prestación económica que aplica a quién se encuentre en riesgo de vulnerabilidad económica. Esto significa que el IMV se configura como un derecho que actúa únicamente para todos aquellos que se encuentren en una situación específica. Definir esta situación específica de "vulnerabilidad económica" es uno de los puntos clave en los que el legislador español ha debido esforzarse en resolver, cosa que hace en torno a criterios económicos precisos muy bien detallados en su artículo 8o. estableciendo un mínimo de ingresos y rentas a partir del cual se es apto para solicitar el IMV; ${ }^{25}$ pero es que además también ha establecido una doble jerarquía entorno al ejercicio y disfrute de este derecho: personas beneficiarias, y personas titulares del IMV.

25 Artículo 8.2: "Se apreciará que concurre este requisito cuando el promedio mensual del conjunto de ingresos y rentas anuales computables de la persona beneficiaria individual o del conjunto de miembros de la unidad de convivencia, correspondientes al ejercicio anterior, en los términos establecidos en el artículo 18, sea inferior, al menos en 10 euros, a la cuantía mensual de la renta garantizada con esta prestación que corresponda en función de la modalidad y del número de miembros de la unidad de convivencia en los términos del artículo 10. A efectos de este real decreto-ley, no computarán como ingresos los salarios sociales, rentas mínimas de inserción o ayudas análogas de asistencia social concedidas por las comunidades autónomas, y otros ingresos y rentas de acuerdo con lo previsto en el artículo 18". 
Esta revista forma parte del acervo de la Biblioteca Jurídica Virtual del Instituto de Investigaciones Jurídicas de la UNAM

Las personas beneficiarias se dividen en dos categorías: aquellas que integren una unidad de convivencia y aquellas que vivan solas ((Real Decreto-ley 20/2020, art. 4o.). La unidad de convivencia es un concepto que lejos de estar indeterminado, queda descrita en el artículo 6.1 de la citada norma en los siguientes términos:

Se considera unidad de convivencia la constituida por todas las personas que residan en un mismo domicilio y que estén unidas entre sí por vínculo matrimonial o como pareja de hecho (...), o por vínculo hasta el segundo grado de consanguinidad, afinidad, adopción, y otras personas con las que conviva en virtud de guarda con fines de adopción o acogimiento familiar permanente.

A esta descripción se añaden importantes excepciones relativas a fallecimientos (6.1), víctimas de violencia de género (6.2, inciso a), separación o divorcio (6.2, inciso b), y una muy interesante referida a los cohabitantes que no entren en los casos anteriores (6.3, inciso c); entendiéndose también todas ellas como unidades de convivencia, y también la exigencia de un tiempo mínimo de convivencia continuada de un año previo a la solicitud (artículo 7.3).

Para aquellas personas que viven solas se establece un rango de edad (comprendido entre los 23 y los 65 años) fuera del cual no pueden ser considerados beneficiarios, además de ostentar el estado civil de soltería y de no formar parte de otra unidad de convivencia. Destaca en este punto la no exigibilidad de estos requisitos para las mujeres víctimas de violencia de género o de trata de seres humanos y explotación sexual decretadas en el artículo 4.1, inciso b, segundo párrafo del Real Decreto-ley 20/2020. Por el contrario, quedan excluidas todas aquellas personas que ya estén percibiendo de modo permanente otras prestaciones de servicio residencial, de carácter social, sanitario o socio sanitario.

Pero ser beneficiario del IMV, no implica ser titular de éste (artículo 5o.). La titularidad, en el caso de la solicitud por parte de una unidad de convivencia, queda reservada para un único representante de la citada unidad. En el caso de aquel beneficiario que vive sólo si coinciden ambas categorías. Esta separación entre beneficiario y titular evita duplicidades y posibles abusos picarescos alrededor de este recurso público.

Además de encontrarse en la ya descrita "situación de vulnerabilidad económica", los beneficiarios deben cumplir con otros requisitos, tales 
Esta revista forma parte del acervo de la Biblioteca Jurídica Virtual del Instituto de Investigaciones Jurídicas de la UNAM

como ostentar la residencia legal y efectiva en España durante al menos el año inmediatamente anterior a la solicitud, y, en el caso de los desempleados mayores de edad o emancipados, figurar inscritos como demandantes de empleo (Real Decreto-ley 20/2020, art. 7o.).

Es posiblemente en estos dos puntos en donde la normativa española nos resulta más relevante: definición de "vulnerabilidad económica" en función de criterios económicos tangibles y concretos, y segmentación del ámbito subjetivo de aplicación en dos categorías diferentes (titular y beneficiario), junto con el establecimiento del concepto de "unidad de convivencia".

Respecto a la acción protectora, ésta queda concretada en una prestación económica, efectiva mensualmente, para cuya determinación se han fijado rígidos criterios que estructuran de modo escalonado la cuantía a percibir por el beneficiario individual o unidad de convivencia (Real Decreto-ley 20/2020, arts. 10 y 18), la cual puede ir desde los 460 hasta los $1015 €$.

La duración del derecho a percibir esta prestación económica se supedita a que los criterios que dieron lugar a ella continúen vigentes (Real Decreto-ley 20/2020, art. 12). Del mismo modo, la cuantía de la prestación se puede ver modificada y actualizada anualmente, si cambian las circunstancias personales, económicas o patrimoniales del beneficiario del IMV o de alguno de los miembros de la unidad de convivencia (Real Decreto-ley 20/2020, art. 12). Asimismo, la normativa española prevé la suspensión, o incluso extinción, del derecho si se pierden algunos de los requisitos necesarios, si se incumplen las obligaciones asumidas (descritas en el artículo 33) o las condiciones asociadas a la compatibilidad del IMV con las rentas e ingresos propios, o si se renuncia al derecho (Real Decreto-ley 20/2020, arts. 14 y 15). Para ello, se establecen también una serie de infracciones y sanciones que aseguren el cumplimiento adecuado de la medida (Real Decreto-ley 20/2020, capítulo VIII).

En aras a hacer efectiva la debida ejecución de este derecho, y a evitar los abusos e infracciones en torno al mismo, se crea un nuevo organismo denominado "Comisión de seguimiento del IMV" (Real Decreto-ley 20/2020, art. 30), la cual evalúa el impacto del IMV como instrumento para prevenir el riesgo de pobreza y exclusión social de las personas en situación de vulnerabilidad económica, da seguimiento a la cooperación 
Esta revista forma parte del acervo de la Biblioteca Jurídica Virtual del Instituto de Investigaciones Jurídicas de la UNAM

intra e interadministrativa necesaria para el desarrollo y aplicación de la norma, y vigila el buen funcionamiento de esta herramienta jurídica.

Respecto al aspecto del costo económico que conllevará la implementación del IMV español y la proyección del número de beneficiarios, el Ministerio de Inclusión, Seguridad Social y Migraciones (departamento encargado de la medida) hizo una estimación inicial de un millón de hogares, ${ }^{26}$ que finalmente acabo rebajando a 850.000 donde residen 2.3 millones de personas, y la Ley de Presupuestos Generales del Estado para $2021^{27}$ ha destinado 3017 millones de $\operatorname{euros}^{28}$ para el IMV, de un total consolidado de 550.484 millones de cuantía total (es decir, un 1.82\% del gasto público total para el año entrante). El costo económico de esta medida no supone por lo tanto un esfuerzo inasumible para las arcas públicas, se constituye como una prestación social no contributiva y se financia a través de la recaudación impositiva.

Debido al corto periodo de vida de la medida (el Real Decreto-ley 20/2020 del 29 de mayo entro en vigor el 1o. de junio de 2020, y el IMV se pudo reclamar a partir del 15 de junio; mientras que este artículo se entregó para su publicación el 1o. de julio de 2020 y se revisó a finales de noviembre del mismo año) falta perspectiva suficiente y datos fácticos (y por supuesto jurisprudenciales) para poder llevar a cabo un análisis más profundo de su funcionamiento y puesta en práctica. Hasta el momento, los aspectos criticables del IMV español se centran en la dificultosa labor burocrática que afecta al particular que desea realizar la solicitud, y en cierta rigidez en los requisitos de acceso. Los obstáculos percibidos por los ciudadanos que más se repiten son las quejas de imposibilidad de concreción de citas en el Servicio Público de Empleo Estatal (SEPE) (organismo público mediante el cual se tramita la prestación), y la lentitud en la tramitación, así como la larga espera para la recepción del ingreso económico.

26 Declaraciones del ministro José Luis Escrivá en la entrevista realizada en la Cadena Ser el 16 de abril de 2020.

27 En el momento de redacción de este trabajo la Ley de Presupuestos Generales del Estado todavía no ha sido aprobada por el Congreso de los Diputados Español, pero el Gobierno ya ha asegurado los votos necesarios para para su aprobación. La votación definitiva se celebrará entre el 30 de noviembre y el 3 de diciembre de 2020.

28 El equivalente a 72,400 millones de pesos mexicanos. 
Esta revista forma parte del acervo de la Biblioteca Jurídica Virtual del Instituto de Investigaciones Jurídicas de la UNAM

Por lo que concierne a los datos sobre su efectividad, en los escasos meses que la medida lleva operando, el Instituto Nacional de la Seguridad Social (INSS) ha recibido más de un millón de solicitudes. No obstante, de ellos 40.000 estaban duplicados o vacíos, reduciendo de esta manera los expedientes válidos a 975.000. De estos se han tramitado 488.000, de los cuales 328.000 han sido resueltos, y a 160.000 se les ha pedido que subsanen errores. De los resueltos, se concedieron 136.000 (correspondientes a 400.000 beneficiarios, ya que se concede por hogar), por el contrario, 192.000 solicitudes fueron denegadas. Entre las causas más comunes de rechazo figuran errores en el empadronamiento, fallos en la declaración de la renta o superar niveles de renta y patrimonio. ${ }^{29}$

Ante el alto nivel de solicitudes denegadas (casi un 20\%), y las quejas antes especificadas, se corre el riesgo de que esta política pública sea percibida como mera propaganda vacía, o al menos como una contradicción permanente entre los grandes anuncios gubernamentales, y la falta de recursos administrativos a disposición del ciudadano para que efectivamente se resuelva su demanda. Por otro lado, una lenta y tardía evaluación de ésta implicará irremediablemente fallos en su eficacia y en la consecución de la finalidad para la que fue diseñada.

Por ello, el gobierno español llevo a cabo en septiembre de 2020 (sólo 3 meses después de su entrada en vigor) un ajuste en los requisitos de acceso a la prestación para flexibilizarlos. ${ }^{30}$ Esta rápida reacción demuestra, a nuestro juicio, un verdadero interés por parte del gobierno en que la medida tenga éxito, no en vano era una de las medidas estrella del gobierno de coalición.

En definitiva, aunque la adopción del IMV como un derecho de alcance general para toda España sea reciente (no así para el ámbito auto-

29 Todo ello según datos ofrecidos por el secretario de Estado de la Seguridad Social y Pensiones, Israel Arroyo en sede parlamentaria ante la Comisión de Trabajo, Inclusión, Seguridad Social y Migraciones del Senado español el 25 de noviembre de 2020.

30 Ajustes localizados en disposiciones transitorias cuarta (de procedimientos para el reconocimiento del ingreso mínimo vital iniciados antes de la entrada en vigor del presente real decreto-ley en los que no se haya dictado resolución expresa) y final undécima (de la modificación del Real Decreto-ley 20/2020, del 29 de mayo, por el que se establece el ingreso mínimo vital) del Real Decreto-ley 28/2020, del 22 de septiembre, de trabajo a distancia.

Esta obra está bajo una Licencia Creative Commons

Atribución-NoComercial-SinDerivar 4.0 Internacional, IIJ-UNAM.

Boletín Mexicano de Derecho Comparado, núm. 160, enero-abril de 2021, pp. 237-276. 
Esta revista forma parte del acervo de la Biblioteca Jurídica Virtual del Instituto de Investigaciones Jurídicas de la UNAM

nómico), y por lo tanto resulte prematuro valorar sus efectos, ${ }^{31}$ observamos una coincidencia en las circunstancias que propician la implementación de este instrumento en España con las de la situación social mexicana, más extremas aún en términos de desigualdad y riesgo de exclusión y vulnerabilidad económica. Por todo ello, y porque la concurrencia con el estado español en cuanto a vocación de protección social se infiere de nuestros textos constitucionales y de la propia concepción del estado social democrático de derecho que compartimos, entendemos esta regulación como una fuente de inspiración para el potencial desarrollo en nuestro país de una institución jurídica semejante.

\section{EL DMV EN MÉXICO}

En este apartado abordamos el otro sujeto del estudio comparado: el tratamiento y regulación del DMV (y su consiguiente materialización en ingreso mínimo vital) en México. Para ello, analizaremos en primer lugar de qué manera este derecho encuentra acogida de forma innominada en nuestra Constitución; posteriormente, cómo se regula en algunas de las diferentes legislaturas estatales; para finalizar con el análisis de su alcance según los criterios de la Suprema Corte de Justicia de la Nación (SGJN).

\section{El DMVy la Constitución Política de los Estados Unidos Mexicanos (CPEUM)}

¿Se encuentra reconocido el DMV en nuestra carta fundamental? Aunque nuestra Constitución data de 1917 ha sido objeto de reforma en numerosas ocasiones, la más importante tuvo lugar en 2011 cuando se incorporó el nuevo paradigma de los derechos humanos. Mediante esta reforma se dejaron de considerar los derechos dentro del texto constitucional como garantías individuales, asignándose como derechos humanos, lo cual resulta un concepto más amplio y menos limitativo que el anterior. Además, la misma norma amplía el espectro de reconocimiento de derechos y su interpretación no sólo derechos establecidos en la norma

31 Debido a la inmediatez entre la aprobación de la medida y la redacción del artículo no disponemos de datos fácticos o jurisprudencia alguna para enriquecer nuestro análisis. 
Esta revista forma parte del acervo de la Biblioteca Jurídica Virtual del Instituto de Investigaciones Jurídicas de la UNAM

fundamental, sino también en los tratados internacionales reconocidos por México; incluyendo también la posibilidad de interpretar los derechos fundamentales en materia de derechos humanos de forma exegética y teleológica, lo que implica terminar con la antigua teoría de que solamente los derechos enumerados dentro del texto de la ley son verdaderos derechos.

Decimos esto, porque según nuestro criterio el DMV en el marco constitucional es un derecho innominado, es decir: este derecho no aparece como tal enunciado en la CPEUM, pero si se puede deducir de la misma. Ahora bien, para comprenderlo es necesario analizar el texto constitucional de manera hermenéutica junto con las normas sobre derechos humanos aceptadas por México. Siguiendo la lógica de la norma, aunque los tratados internacionales no hagan mención literal de este derecho puede inferirse de igual forma de nuestra Constitución. Incluso partiendo desde la óptica que otros Estados ya lo han inferido de estos tratados se puede concluir que también es posible hacer lo mismo en nuestro país. El deducir o desprender de los tratados internacionales reconocidos por México o de los propios preceptos constitucionales el DMV es legítimo según el mandato constitucional. Queda claro que al tratarse de un derecho innominado manifiesta problemas sobre sus dimensiones, pero esto no le resta valor normativo: limitar un derecho por dicha problemática atenta contra el espíritu de la norma.

El primer parámetro para considerar al DMV como un verdadero derecho es el artículo primero constitucional. Las reglas para la interpretación jurídica que se instauran en este precepto, junto con las directrices y obligaciones que establecen apoyarían esta incorporación. Resultando que la interpretación de estas normas debe ser congruente con el principio pro persona, y en el caso que nos ocupa aplicar al concepto de dignidad humana la interpretación más favorable (CPEUM, art. 1o.).

Abundando en este sentido, debemos recordar que los derechos humanos son indivisibles, interdependientes, se implican los unos a los otros, y deben ajustarse teniendo en cuenta el principio de progresividad. En observancia de los principios rectores enunciados resulta lógico que para tener garantizada una protección real de la dignidad humana no se pueda apartar al individuo de los derechos que le permitan un desarrollo óptimo. Para que dicho desarrollo sea posible se requiere el goce real de las condiciones necesarias que le permitan el ejercicio, no solamente de un grupo

Boletín Mexicano de Derecho Comparado, núm. 160, enero-abril de 2021, pp. 237-276. 
Esta revista forma parte del acervo de la Biblioteca Jurídica Virtual del Instituto de Investigaciones Jurídicas de la UNAM

de derechos, sino de los derechos en general. En este caso el mínimo vital es el núcleo esencial para que los demás derechos puedan satisfacerse de acuerdo con los fines perseguidos al establecer la dignidad humana como una base y un fin en sí mismo.

Encontramos a lo largo de nuestro texto constitucional una serie de referencias en su parte dogmática que refuerzan esta óptica que proponemos.

El artículo 3o. de la CPEUM, aunque centrado principalmente en la educación, fija un principio que coincide con las bases y fines de un Estado social y democrático de derecho cuando en su fracción segunda inciso a establece que el sistema educativo "será democrático considerando a la democracia no solamente como una estructura jurídica y un régimen político, sino como un sistema de vida fundado en el constante mejoramiento económico, social y cultural del pueblo". Así pues, la vida democrática no puede ser ajena a los fenómenos sociales, económicos y culturales que afectan a los ciudadanos. Por lo que problemas como la pobreza, la marginación y las dificultades para acceder a los bienes primarios y al desarrollo adecuado afectan a la calidad de nuestra democracia y se encuentran en relación directa con el DMV y en su consolidación como derecho humano (J. F. González Salas, 2013).

El artículo 4o. de la CPEUM garantiza por parte de los poderes públicos distintos derechos de contenido social, económico y cultural, entre los que destacan el derecho a una "alimentación nutritiva, suficiente y de calidad"; el derecho a la protección a la salud; el derecho al "acceso, disposición y saneamiento de agua para consumo personal y doméstico en forma suficiente, salubre, aceptable y asequible"; y el derecho "a disfrutar de vivienda digna y decorosa". Todos ellos son derechos que incluyen, afectan, se relacionan y se engloban en el DMV.

El artículo 5o., aunque desde el enfoque de la libertad de trabajo o de actividad productiva, establece el derecho a una justa retribución. Este precepto debe interpretarse de forma relacionada con el artículo 123, ya que en él se perfeccionan los derechos de los trabajadores, entre ellos el salario mínimo. En este sentido, cabe destacar que el artículo 123 fija como principio la justicia social y la distribución equitativa de las riquezas, lo cual se encuentra reconocido en distintos ordenamientos internacionales, entre ellos la Carta Social de las Américas (Asamblea General de la OEA, 4/06/2012). 
Esta revista forma parte del acervo de la Biblioteca Jurídica Virtual del Instituto de Investigaciones Jurídicas de la UNAM

Los artículos 25, 26, 27 y 28 de la CPEUM son de suma importancia para la aplicación por parte del Estado de los derechos económicos, sociales y culturales. En virtud que en ellos se fijan los principios de la economía nacional, y el papel del Estado frente a los sectores sociales y privados. Particularmente, el artículo 28, párrafo tercero, que suele identificarse por la prohibición de prácticas monopólicas, contiene ciertas obligaciones para proteger el consumo de artículos necesarios y fija bases para proteger a las personas en general el acceso a los productos y artículos de consumo necesario. Por otra parte, el artículo 31 enumera las obligaciones de los ciudadanos mexicanos, y en su fracción IV contiene las de carácter fiscal. Las contribuciones deben satisfacer dos condiciones: que sean proporcionales y equitativas, además de cumplir con el principio de legalidad. Por lo tanto, las contribuciones para ser consideradas constitucionales deben tomar en cuenta la capacidad contributiva de los individuos, lo que en relación con el DMV se referiría a la afectación o la disminución del patrimonio o capital de los gobernados. La norma constitucional establece la obligación de contribuir, pero también establece limitantes. Otro principio que se deriva de la interpretación de este precepto, según lo fijo la SCJN, es la razonabilidad tributaria que consiste en que el tributo sea razonable con la finalidad que perseguida (S. F. de la Garza, 2008). Esto con la finalidad de dar coherencia a las contribuciones que fije el Estado, las cuales deben respetar los derechos de los contribuyentes.

De este modo, observamos como la CPEUM se configura como un texto plagado de referencias constitucionales en las que anclar este reconocimiento como derecho innominado del DMV por el que abogamos. Nuestra carta magna se encuentra trufada de menciones y enumeraciones de la mayor parte de las prerrogativas que componen el DMV según su concepción en el ámbito internacional. Interpretar la misma a la luz de las diversas normas internacionales de los que el Estado mexicano constituye una obligación y un compromiso adoptado por nuestra Constitución.

\section{Reconocimiento del DMV en el ámbito estatal}

$\mathrm{Al}$ estructurarse México como un Estado de tipo federal, nuestro sistema normativo comprende también la multitud de regulaciones que se desarrollan en las 32 entidades federativas. Por ello, ahora dedicamos 
Esta revista forma parte del acervo de la Biblioteca Jurídica Virtual del Instituto de Investigaciones Jurídicas de la UNAM

nuestra atención al modo en el que el objeto de nuestro estudio ha sido abordado por algunas de las constituciones locales.

En este ámbito podemos encontrar aportaciones de elementos para la conceptualización e incorporación del DMV dentro del marco normativo de nuestro país. Es importante puntualizar que los órdenes jurídicos de las entidades federativas, por los principios del pacto federal y supremacía constitucional deben respetar la Constitución federal. Por ende, las constituciones y las autoridades locales deben respetar este compromiso de cumplimiento de las normas sobre derechos humanos. Pero es que, además, las constituciones locales pueden ampliar o especificar con mayor detalle los derechos humanos y las obligaciones para las autoridades tanto estatales como municipales, así como extender la protección a los derechos humanos en toda aquella materia que no se encuentre de forma exclusiva para la competencia federal.

En efecto, el cambio de garantías individuales a derechos humanos no se ha reducido al ámbito federal, y su asimilación no ha sido de forma homogénea, como expone Juan Manuel Acuña:

A nivel local, y desde hace unos años, inició un proceso análogo, aunque asimétrico, respecto al proceso federal. Algunos estados reformaron sus Constituciones para robustecer el catálogo de derechos e incorporar mecanismos de justicia constitucional local. (2015, pp. 1-15)

En estas circunstancias, lo que las constituciones locales pueden aportar para el derecho al mínimo existencial, varía según la entidad federativa. En la mayoría de las constituciones estatales el DMV sigue siendo un derecho innominado al igual que en la Constitución federal. Aun así, algunas constituciones locales establecen de forma más detallada la adopción y cumplimiento de los derechos sociales.

Dadas las limitaciones de extensión que este artículo plantea, sumadas al inmenso número de constituciones locales (32) excede por mucho de nuestro propósito llevar a cabo un análisis pormenorizado de cada una de ellas. Por eso, hemos seleccionado, a nuestro juicio, la más relevante: Ciudad de México, como la más avanzada y explícita.

Dentro de su carta de derechos (correspondiente con su título primero), y en su capítulo II dedicado a los derechos humanos, la Constitución Política de la Ciudad de México (CPCDMX), dispone en su artículo 9.1 
Esta revista forma parte del acervo de la Biblioteca Jurídica Virtual del Instituto de Investigaciones Jurídicas de la UNAM

denominado "Ciudad solidaria" como parte del derecho a la vida digna que "las autoridades adoptarán las medidas necesarias para que progresivamente se erradiquen las desigualdades estructurales y de pobreza", con el fin de conseguir una "justa distribución de la riqueza y del ingreso entre personas, familias, grupos sociales y ámbitos territoriales". Específicamente el artículo 9.2 reconoce de modo explícito el DMV con la siguiente redacción: "Todas las personas tienen derecho a un mínimo vital para asegurar una vida digna en los términos de esta Constitución". Dicho artículo además agrega en su apartado tercero que se garantizaran los derechos progresivamente "hasta el máximo de los recursos públicos disponibles".

En su artículo 17 sobre el "Bienestar social y economía distributiva" la CPCDMX plantea algunas obligaciones y principios que deben seguir las autoridades para regir la vida social y económica. Resulta destacable el hecho de incorporar en dicho precepto el concepto de Estado social y democrático como aspiración. En su apartado A, dedicado a la política social, refiere lo siguiente sobre el DMV:

Se establecerá y operará un sistema general de bienestar social, articulado, incluyente, participativo y transparente vinculado a la estrategia de desarrollo redistributivo, al que concurrirán las instancias encargadas de las materias correspondientes. El sistema considerará al menos los siguientes elementos: (...) Los mecanismos para hacer efectivo el derecho al mínimo vital para una vida digna, dando prioridad a las personas en situación de pobreza, que se establecerán de conformidad con los criterios de progresividad, con los indicadores que determine el organismo constitucional federal competente y las metas evaluables que fije el organismo local correspondiente (...).

En este inciso pues, la CPCDMX establece el mínimo vital como un derecho universal, proponiendo otorgar prioridad a las personas en estado de pobreza. Es preciso apuntar que el texto en cuestión establece varios indicadores, pero no ofrece una definición limitada o exacta de qué es el mínimo vital. Esto empuja a que la comprensión de la dimensión teleológica de este derecho sea indispensable para su debida aplicación, y del mismo modo podemos entenderlo también como un mayor margen para ejercer su aplicación. Con la inclusión de los aspectos señalados, la CPCDMX se muestra como el mejor ejemplo del reconocimiento e in- 
Esta revista forma parte del acervo de la Biblioteca Jurídica Virtual del Instituto de Investigaciones Jurídicas de la UNAM

corporación del DMV, no en vano se trata de uno de los textos más avanzados y modernos en lo que a derechos sociales se refiere.

En definitiva, el marco normativo local no es ni mucho menos idéntico en cuanto a la regulación de los derechos humanos en general ni por supuesto del DMV en particular. El margen de creación y adaptación normativo estatal no suele aprovecharse o entenderse de la misma forma. Las constituciones locales pueden ser vistas como instrumentos para hacer palpable el reconocimiento a los derechos esenciales a un nivel de interacción más cercano a la población, encontrando su máximo exponente en la CPCDMX que tan inspiradora puede resultar para una regulación federal a estos efectos.

\section{El DMV según los criterios de la $S 7 C \mathcal{N}$}

La SCJN es el más alto tribunal de nuestro país, el cual ejerce el control concentrado para resolver las controversias que existan en torno a las leyes, y su interpretación de acuerdo con la carta fundamental, marcando la pauta por la que se regirán el resto de las instancias jurisprudenciales.

La evolución en torno al reconocimiento del mínimo vital despunta a partir de la reforma constitucional del 2011. El DMV no aparece explícitamente en nuestro texto constitucional, por lo que los tribunales mexicanos deben partir de la interpretación para incorporarlo a nuestro régimen jurídico. Es oportuno señalar que en la actualidad la SCJN no ha emitido una tesis de jurisprudencia que defina al mínimo vital. Existen, sin embargo, tesis jurisprudenciales donde se menciona el mínimo vital y por tanto colaboran para establecerlo en el sistema jurídico. No obstante, se pueden encontrar tesis aisladas que han dado dimensiones y definiciones para comprender este concepto, y en base en estas se han pronunciado las jurisprudencias mencionadas.

Tempranamente, en 2007, encontramos que la Primera Sala de la SCJN realizó una definición del DMV en la tesis aislada 1a. XCVII/2007 (Gaceta del Seminario Fudicial de la Federación. Décima Época). Dicha tesis señala que el mínimo vital "cobra plena vigencia de la interpretación sistemática de los derechos fundamentales", haciendo énfasis en que en un Estado democrático de derecho se requiere que los individuos cuenten con un punto de partida para desarrollar un plan de vida autónoma. Esto 
Esta revista forma parte del acervo de la Biblioteca Jurídica Virtual del Instituto de Investigaciones Jurídicas de la UNAM

guarda similitud con lo propuesto por E. Carmona Cuenca (2012), al vincular el Estado democrático con que el ciudadano cuente con un mínimo vital a partir del cual pueda realmente emprender un desarrollo autónomo. La Primera Sala agrega que para que el individuo pueda llevar una vida libre del temor y la miseria, el Estado debe tomar tanto las medidas que sean necesarias, fijándose la necesidad de evitar que el ser humano se vea reducido inconstitucionalmente en su dignidad por no contar con las condiciones materiales que le permitan una vida digna. Esta tesis con nombre "Derecho al mínimo vital en el orden constitucional mexicano" menciona que este derecho humano resulta particularmente de la interpretación de los artículos 1o., 3o., 4o., 6o., 13, 25, 27, 31 fracción IV y 123.

Con ocasión del foro "Derechos Fundamentales de las Personas Físicas Contribuyentes" (E. Carmona Cuenca, 2012), el ministro José Fernando Franco González Salas trató junto con otros juristas, el DMV (aunque enfocándose dentro del ámbito fiscal), ofreciendo una aproximación a su significado de la cual cabe destacar lo siguiente:

No debe perderse de vista que todas las acciones directas destinadas a satisfacer el mínimo vital de todos los mexicanos requieren de la disposición de los recursos necesarios y que la vía de las exenciones o deducciones tributarias, siendo probablemente muy efectivas para lograr ese objetivo, no son las únicas. El Estado también lo hace a través de los servicios de salud, educación, alimentación, becas y subsidios de diferentes tipos, que implican la erogación de enormes cantidades de dinero que provienen del erario, que se conforma principalmente con los impuestos que pagamos.

De la forma en que se planteó, observamos que el mínimo vital se cumplimenta por medio de diferentes servicios y prestaciones.

En 2009 se incorporó al sistema de tesis el concepto de mínimo exento como una forma de exceptuar de las cargas tributarias a los contribuyentes tomando como referencia la esencia del mínimo vital. Inclusive considerándose como equivalentes o sinónimos ambos conceptos. En cuanto a este mínimo exento de todo gravamen la Primera Sala (Tesis 1a. XVI/2009 sostuvo que es aplicable para aquellos que no cuentan con una capacidad contributiva suficiente, de la siguiente forma:

[...] en razón de que la capacidad económica trasciende a la configuración de dicho mecanismo liberador de pago únicamente en los casos de aquellos 
Esta revista forma parte del acervo de la Biblioteca Jurídica Virtual del Instituto de Investigaciones Jurídicas de la UNAM

causantes que no tienen la capacidad idónea para soportar la imposición que solamente se legitima constitucionalmente cuando la persona supera el nivel del mínimo vital o mínimo exento. (Tesis 1a. X/2009. Gaceta del Semanario fudicial de la Federación. Novena Época, p. 547)

En esta tesis se dispuso que el principio de generalidad tributaria tiene como fin que todas las personas sin distinción aporten al gasto público. Aun así, no debe entenderse que no se tengan excepciones, en este caso el mínimo vital, ya que se debe partir de la capacidad real para contribuir, destacando entre otros aspectos que la dignidad humana prevé que se cuente con un punto de partida para alcanzar un plan de vida autónoma. Esta protección deriva del hecho que las personas cuyos ingresos apenas resulten suficientes para subsistir no deberían verse requeridas a hacer aportaciones, ya que esto "agravaría su ya precaria situación". Conforme a esta tesis se puede apreciar que el mínimo vital está ligado tanto a la dignidad humana, incluso desde un punto de vista económico, como con los principios de solidaridad.

La primera tesis jurisprudencial, con carácter obligatorio que se incorporó en el Semanario Judicial de la Federación y su Gaceta haciendo mención literal del mínimo vital fue en materia tributaria. Esta jurisprudencia fue dictada por la Primera Sala, sosteniendo que la proporcionalidad tributaria debe observarse en relación con la capacidad contributiva atendiendo como limite el mínimo vital. La tesis jurisprudencial 1a./J. 77/2011 (Gaceta del Seminario fudicial de la Federación. Novena Época) que lleva por nombre: "Proporcionalidad tributaria. El legislador cuenta con un margen amplio de configuración, al definir tasas y tarifas" menciona que "los principios constitucionales de la materia tributaria no permiten asumir que exista un sistema de tasas o tarifas justas per se". Podemos concluir que estas tarifas gozan de validez al cumplir con el principio de legalidad, proporcionalidad y equidad, pudiendo existir tarifas distintas siempre y cuando no se agote el patrimonio del causante y no afecte el mínimo vital.

Por otra parte, el mínimo vital también ha aparecido en resoluciones de la SCJN en materia de seguridad social, concretamente en materia de deducciones y disminuciones sobre las pensiones, jubilaciones y otras formas de retiro. En virtud de una tesis aislada (Tesis P. XXXIX/2013. Gaceta del Semanario Judicial de la Federación. Décima Época) derivada del amparo 
Esta revista forma parte del acervo de la Biblioteca Jurídica Virtual del Instituto de Investigaciones Jurídicas de la UNAM

en revisión 32/2011 el Pleno de la SCJN se pronunció sobre las deducciones a diversas formas de retiro, donde tomó como referencia el mínimo vital, sosteniendo que las deducciones realizadas en apego a la Ley del Impuesto sobre la Renta vigente hasta mayo de 2012 no eran contrarias al DMV y respetaban el artículo 31, fracción IV constitucional, ya que dicha ley establecía una exención al pago del impuesto hasta por un monto diario de nueve veces el salario mínimo., considerando esta cantidad suficiente para no violentar el mínimo de subsistencia. ${ }^{32}$

En otra tesis aislada (Tesis P. XXXVII/2013. Gaceta del Semanario fudicial de la Federación. Décima Época) emitida por el Pleno se resolvió en el mismo sentido sobre la exención comentada de la Ley del Impuesto sobre la Renta abrogada, pero haciendo hincapié en artículo 123 aparado A y $\mathrm{B}$ en lo relativo a la inembargabilidad del salario mínimo y su relación con las contribuciones y apuntando que la prohibición constitucional de embargar el salario mínimo no se hace extensiva a las prestaciones del retiro. De igual forma señaló que se respetaba un margen de ingresos libre de gravámenes para satisfacer las necesidades más elementales caracterizado como DMV.

El Pleno de la Suprema Corte en la tesis P. VII/2013 (Gaceta del Semanario fudicial de la Federación. Novena Época) manifestó que el mínimo vital se ha reconocido como un derecho derivado del artículo 31 fracción IV y también como una prerrogativa de no embargabilidad del salario derivado del artículo 123. Aun así, el mínimo vital también abarca un conjunto de medidas negativas y positivas a cargo del Estado, que permitan respetar la dignidad humana en términos del artículo 25 constitucional, referente al desarrollo nacional, por lo que el Estado se encuentra obligado a garantizar la disponibilidad de prestaciones de "procura existencial o asistencia vital".

Por otro lado, el DMV en relación con la materia penitenciaria fue abordado en una acción de inconstitucionalidad. El Pleno de la Suprema Corte dictó una tesis jurisprudencial identificada con el número P./J. 35/2013 (Gaceta del Semanario Fudicial de la Federación. Décima Época), sosteniendo que la Ley que Establece Normas Mínimas sobre Re-

32 Finalmente es oportuno aclarar que la Ley del Impuesto sobre la Renta de 2016 y vigente establece otra cantidad en el artículo 93, fracción IV, siendo de quince veces el salario mínimo el monto exento.

Esta obra está bajo una Licencia Creative Commons

Atribución-NoComercial-SinDerivar 4.0 Internacional, IIJ-UNAM.

Boletin Mexicano de Derecho Comparado, núm. 160, enero-abril de 2021, pp. 237-276. 
Esta revista forma parte del acervo de la Biblioteca Jurídica Virtual del Instituto de Investigaciones Jurídicas de la UNAM

adaptación Social de Sentenciados ${ }^{33}$ actualmente abrogada, violentaba el mínimo vital en su artículo 10 párrafo segundo. En otra jurisprudencia derivada de la misma acción de inconstitucionalidad, el Tribunal Pleno se pronunció de nuevo sobre el mínimo vital en relación con el descuento a los reclusos para cubrir su sostenimiento realizado a la cantidad recibida por su trabajo penitenciario (P./J. 30/2013. Gaceta del Semanario Fudicial de la Federación. Décima Época).

La Segunda Sala de la Suprema Corte (2014) también decidió sobre el DMV en materia de trabajo, al resolver sobre la embargabilidad del salario derivado de la contradicción de tesis $422 / 2013,{ }^{34}$ en observancia de las normas protectoras del salario, dictaminando una protección sobre el mínimo vital. ${ }^{35}$

En resumen, observamos como la SGJN ha dictado diversas tesis vinculadas al mínimo vital enfocado en diferentes materias. También los tribunales colegiados han resuelto cuestiones importantes en materia del mínimo vital. ${ }^{36}$ El hecho de que la jurisprudencia en torno al DMV se haya desarrollado más en determinadas materias no priva de que la protección constitucional al mínimo vital pueda ampliarse y fijar su alcance y límites, algo que estamos seguros de que sucederá como consecuencia de la interpretación evolutiva y progresiva de los derechos humanos.

\section{CONCLUSIÓN: UNA APUESTA POR LA IMPLEMENTACIÓN DEL DMV EN MÉXICO}

33 Publicada en el DOF el 19-05-1971, abrogada en el DOF 16-06-2016.

34 Tesis: 2a./J. 42/2014. Gaceta del Semanario Fudicial de la Federación. Décima Época.

35 En este caso dictaminó que las autoridades jurisdiccionales pueden ordenar el embargo sobre el excedente del salario mínimo. Siendo posible el embargo sobre el treinta por ciento de este excedente, tratándose de obligaciones de carácter civil o mercantil, a excepción de los casos en que se ordene el embargo por parte de una sentencia para asegurar una pensión alimenticia, en cuyo caso puede ser sobre el total del excedente del salario mínimo. Ahora bien, consideró que, para asegurar el mínimo vital de un trabajador, si el salario se encuentra afectado por una pensión alimenticia, sólo puede embargarse por otra deuda sobre el treinta por ciento del salario mínimo que no se encuentra afectado.

36 Destaca la del Noveno Tribunal Colegiado en Materia Administrativa del Primer Circuito: Tesis I.9o.A.1 CS. 2016. Gaceta del Semanario fudicial de la Federación. Décima Época.

Donde al interpretar la tesis emitida por la Primera Sala del alto tribunal constitucional, "Derecho al mínimo vital en el orden constitucional mexicano", se resuelve que el mínimo vital está dirigido a las personas físicas. 
Esta revista forma parte del acervo de la Biblioteca Jurídica Virtual del Instituto de Investigaciones Jurídicas de la UNAM

Hemos observado que el DMV se manifiesta como la sublimación de los derechos humanos de segunda generación, en concreto se erige en epitome de los derechos sociales. Pero la cuestión aquí está en dilucidar si lo hace configurándose como culminación del desarrollo de los derechos humanos económicos, sociales y culturales, o si lo hace a modo de paraguas que contuviese los más básicos de estos derechos (salud, educación, vivienda, alimentación, entre otros) para proporcionarles una especial protección y blindaje. Esto es, si el DMV debe considerarse como un derecho en exclusiva, con un reconocimiento específico, o si es un referente innominado que da cobijo a estos citados derechos que se entienden como "mínimo".

Nuestra postura tiende a ser bastante holística, pero nos decantamos por el reconocimiento del DMV como un derecho independiente y concreto. No obviamos su esencia compleja y poliédrica, más entendemos que el verdadero avance surge al dotar a este derecho de una identidad propia que propicie su materialización efectiva la cual implique su justiciabilidad. Compartimos su doble naturaleza, pero ponemos el acento en las condiciones que garantizan su exigibilidad ante los poderes públicos.

Para todo aquel Estado que se defina a sí mismo como un Estado social y de derecho, la exigibilidad de los derechos humanos por el garantizados es un mínimo ligado inherentemente a su propio ser., deviniendo pues en una obligación fundamental de los Estados asegurar su cumplimiento, y también un parámetro de observancia del cumplimiento de las normas internacionales a las que se encuentre suscrito. México se cuenta entre los Estados que han firmado y ratificado el Pacto Internacional de Derechos Económicos Sociales y Culturales, el cual reconoce y protege estos derechos humanos, entendidos igualmente como indispensables para el ejercicio de otras categorías de derechos humanos por su carácter indivisible. Así pues, es posible concluir que la exigibilidad del DMV es además una forma de hacer efectiva la reclamación de otros derechos humanos.

En 2018 el Comité de Derechos Económicos Sociales y Culturales realizó unas observaciones a México ${ }^{37}$ derivado de los informes presentados por nuestro país, y aunque se reconocieron aspectos positivos en de-

37 Observaciones finales a los informes periódicos quinto y sexto combinados de México. 28 Sesión del Comité de Derechos Económicos, Sociales y Culturales de la ONU, 29 de marzo de 2018.

Esta obra está bajo una Licencia Creative Commons

Atribución-NoComercial-SinDerivar 4.0 Internacional, IIJ-UNAM.

Boletin Mexicano de Derecho Comparado, núm. 160, enero-abril de 2021, pp. 237-276. 
Esta revista forma parte del acervo de la Biblioteca Jurídica Virtual del Instituto de Investigaciones Jurídicas de la UNAM

fensa de estos derechos, también se señalaron varias preocupaciones relativas a la justiciabilidad de los mismos. Entre ellas destaca las "dificultades para acceder a recursos judiciales efectivos", por lo que recomienda tomar las medidas necesarias para hacer exigibles estos derechos en todos los niveles de nuestro sistema judicial. En materia fiscal el Comité recomendó al Estado mexicano aumentar los esfuerzos para lograr una política fiscal más equitativa desde un enfoque social que le permita asegurar recursos necesarios para lograr de acuerdo con el principio de progresividad la efectividad de los derechos económicos, sociales y culturales. En cuanto a la aplicación del presupuesto, debe implementarse y formularse de manera que garantice a todos los individuos los derechos en cuestión, en especial los desfavorecidos y marginados. En materia de seguridad social indicó que se deben continuar los esfuerzos por conseguir una protección social universal, y que dicha protección social incluya "garantías sociales universales esenciales". El Comité también dio recomendaciones para efecto de combatir la pobreza: solicitó que se establezcan metas específicas y se implementen mecanismos de coordinación entre las instituciones, así como que los programas sociales de lucha contra la pobreza sean acordes a los principios de los derechos humanos, y que deben contar con los recursos suficientes para efectuar su exigibilidad. En materia de trabajo, se agregaron diligencias sobre el salario mínimo, salud, la economía informal o el acceso y saneamiento de agua. Pero, ante todo, es importante señalar que se exhortó a nuestro país para a ratificar el Protocolo Facultativo del Pacto Internacional de Derechos Económicos, Sociales y Culturales.

En la actualidad, y como respuesta a los efectos económicos adversos causados por la pandemia, la CEPAL también ha propuesto que se distribuya un ingreso básico temporal de emergencia y un bono contra el hambre durante seis meses para combatir el problema de la pobreza extrema generada por el COVID-19. (CEPAL, 2020)

Atendiendo a estas observaciones, y como herramienta de solución de estas deficiencias, proponemos la regulación en México del DMV en un modo similar al adoptado por España: mediante la implementación del IMV. A nuestro juicio, resulta más factible, equilibrador de desigualdades y justa la implementación del IMV en lugar de la RBU Afirmamos esto en base a las razones aportadas en el apartado correspondiente que pueden resumirse en una concepción social de lo público frente a la 
Esta revista forma parte del acervo de la Biblioteca Jurídica Virtual del Instituto de Investigaciones Jurídicas de la UNAM

redistribución igualitarista liberal. Para nosotros, el único instrumento que garantiza el desarrollo del DMV es el IMV.

Venimos de contemplar como en el país europeo (con el que nos vemos unidos a través de fuertes lazos y similitudes, entre ellas una semiótica social y jurídica común) el IMV ha sido concebido como un instrumento de satisfacción de unas condiciones materiales mínimas que desencadene la transición de aquellos que se encuentran en un escenario de exclusión social, hacia otro en la que se puedan desarrollar con plenitud en la vida social y económica, rompiendo el vínculo entre ausencia estructural de recursos y falta de acceso a oportunidades. El DMV se configura no sólo como una política dirigida a grupos concretos en situación de vulnerabilidad extrema, sino como una forma de protección estructural de la sociedad en su conjunto (Real Decreto-ley 20/2020, preámbulo, punto III). Si bien todavía carecemos de datos suficientes como para poder llevar a cabo una crítica completa de la experiencia española, en nuestra humilde opinión entendemos que, dadas las circunstancias actuales, se presenta la ocasión perfecta para abrir el debate, y tomar la experiencia española como referencia puede ser un buen punto de partida.

En la reciente reforma de la constitución local de Ciudad de México, se ha incluido el DMV. Es el momento de emprender el mismo camino a nivel federal.

\section{FUENTES}

AGuÑA, J. M. (2015). Constitucionalismo local, federalismo judicial y derechos humanos. En Héctor FiX-Fierro, Miguel CARbonell y Diego VALADÉS (coords.), Estado constitucional, derechos humanos, justicia y vida universitaria. Estudios en homenaje a Forge Carpizo. Derechos humanos, vol. 1, (pp. 1-15). México: UNAM, Instituto de Investigaciones Jurídicas.

GutTman, A. (2003). En Taylor, C. El multiculturalismo y la política del reconocimiento. Fondo de Cultura Económica.

Carmona Cuenca, E. (2017). El derecho al mínimo vital y el derecho a la renta básica. Anuario de Derechos Humanos, 199-209.

Carmona Cuenca, E. (2012). El derecho a un mínimo vital con especial referencia a la Constitución Española de 1978. Estudios Internacionales, 61-85. 
Esta revista forma parte del acervo de la Biblioteca Jurídica Virtual del Instituto de Investigaciones Jurídicas de la UNAM

Duque Quintero, S. P., Duque Quintero, M. y González Sánchez, P. (2019). Sobre el derecho fundamental al mínimo vital o a la subsistencia: análisis jurisprudencia. Encuentros, 17(1), pp. 80-95.

Espinoza de los Monteros, J. (2013). Los desafíos del constitucionalismo social del siglo XXI. En César Astudillo Reyes y Jorge Carpizo (coords.), Constitucionalismo. Dos siglos de su nacimiento en América Latina (pp. 375-391). México: UNAM, Instituto de Investigaciones Jurídicas.

Ferrajoli, L. (2011). Principia iuris. Teoría del derecho y de la democracia. Trotta.

Gala Durán, C. (2020). Los desafíos del nuevo ingreso mínimo vital. IUSLabor. Revista d'anàlisi de Dret del Treball (2), 1-4.

GarZA, S. F. de la (2008). Derecho financiero mexicano. Porrúa.

GOerLich Gisbert, F. (2016). Distribución de la renta, crisis económica y políticas redistributivas. Fundación BBVA.

GOnZÁlez SALAS, J. F. (2013). Derechos fundamentales de las personas físicas contribuyentes. Memorias del Foro: "Derechos Fundamentales de las Personas Físicas Contribuyentes". CDMX.

INDACOECHEA PREVOST, Ú. (2011). El derecho al mínimo vital. Un análisis de su posible fundamentación como derecho humano. En P. GRANDÉZ, El derecho frente a la pobreza. Los desafíos éticos del constitucionalismo de los derechos (pp. 259, 265, 266 y 283).

MARTÍNEZ ViRTO, L. (2019). Nueva pobreza, precariedad y rentas mínimas: respuestas para incentivar el empleo en el actual contexto sociolaboral. Cuadernos de Relaciones Laborales (37), 155-175.

Monereo Pérez, J. L. y RodríGuez Iniesta, G. (2020). El derecho social fundamental a la existencia digna y el ingreso mínimo vital. Revista de Derecho de la Seguridad Social. Laborum (24), 13-35.

Pelayo Möller, C. M. (2012). El "mínimo vital” como estándar para la justiciabilidad de los derechos económicos, sociales y culturales. $R e-$ vista Electrónica Méthodos (3).

Pérez GonzÁlez, E. y Nettel Barrera, A. (2017). El derecho al mínimo vital frente a la inactividad administrativa en la protección a los derechos humanos. Revista Digital de Derecho Administrativo, 317-337.

Petit Guerra, L. A. (2019). ¿En qué estado del debate se encuentra la jurisprudencia latinoamericana en cuanto al desarrollo del derecho al mínimo vital? Entre la vanguardia y la retaguardia. Revista furídica Derecho, 8(10), 56-67. 
Esta revista forma parte del acervo de la Biblioteca Jurídica Virtual del Instituto de Investigaciones Jurídicas de la UNAM

Ramos QUinTana, M. I. (2020). El ingreso mínimo vital como instrumento para combatir la pobreza y la exclusión desde el sistema de la seguridad social. Hacienda Canaria (53), 295-319.

RAWLS, John (1971). Teoría de la justicia (2e. ed.), trad. de M. D. González. The Belknap Press of Harvard University Press.

REY PÉREZ, J. L. (octubre 2020-marzo 2021). Renta básica universal. Eunomia: Revista en Cultura de la Legalidad (9), 237-257.

Rodríguez GAMAREnA, C. (2014). La exigibilidad de los derechos sociales a partir de su estructura. Ciencia furídica, 3(6), 52.

Rosales García, C. M. (2016). Reconociendo y comprendiendo la naturaleza del mínimo vital. Criterio furídico, 16(2), 113-140.

Sala Franco, T. y MARTín-POzUelo LóPez, Á. (2020). El ingreso mínimo vital. El sistema español de rentas minimas. Tirant lo Blanch.

Silva MezA, J. (2014). El derecho al mínimo vital: su contenido y relevancia. En Magdalena CERvantes AlCAYde et al. ¿Hay justicia para los derechos económicos, sociales y culturales? Debate abierto a propósito de la reforma constitucional en materia de derechos humanos (pp. 213-240). México: UNAM-Suprema Corte de Justicia de la Nación.

Tena Gamporesi, A. (2018). La renta básica universal basada en la evidencia. Política y Sociedad, 55(13), 851-871.

VAN PARIJS, P. (1996). Libertad real para todos (qué puede justificar el capitalismo si hay algo que pueda hacerlo). Paidós.

VAn PARIJS, P. (2001). Basic Income: a Simple and Powerful Idea for the 21st Century. Politics \& Society, 32(1), 7-39.

VAn Parijs, P. (2020). Basic income: Finland's final verdict. Social Europe. https://wrere.socialeurope.eu/basic-income-positive-results-from-finland

WALZER, M. (1983). Spheres of justice: A defense of pluralism and equality. Blackwell. Trad. cast. (1991). Las esferas de la justicia. una defensa del pluralismo y la igualdad. Fondo de Cultura Económica.

\section{Criterios judiciales}

Sentencia 37/1994 del Tribunal Constitucional de España.

Tesis 1a. X/2009. Gaceta del Semanario fudicial de la Federación. Novena Época. Tesis 1a. XVI/2009. Gaceta del Semanario Fudicial de la Federación. Novena Época. 
Esta revista forma parte del acervo de la Biblioteca Jurídica Virtual del Instituto de Investigaciones Jurídicas de la UNAM

Tesis 1a./J. 77/2011. Gaceta del Semanario Judicial de la Federación. Novena Época.

Tesis aislada 1a. XCVII/2007. Gaceta del Semanario Fudicial de la Federación. Novena Época.

Tesis I.9o.A.1 CS. Gaceta del Semanario fudicial de la Federación. Décima Época.

Tesis P. VII/2013. Gaceta del Semanario Judicial de la Federación. Novena Época.

Tesis P. XXXIX/2013. Gaceta del Semanario Judicial de la Federación. Décima Época.

Tesis P. XXXVII/2013. Gaceta del Semanario Fudicial de la Federación. Décima Época.

Tesis P./J. 30/2013. Gaceta del Semanario Fudicial de la Federación. Décima Época.

Tesis P./J. 35/2013. Gaceta del Semanario Fudicial de la Federación. Décima Época.

Tesis: 2a./J. 42/2014. Gaceta del Semanario Judicial de la Federación. Décima Época.

Legislación

Carta Social de las Américas, 2012, Asamblea General de la OEA.

Constitución Española 1978.

Constitución Política de la Ciudad de México, 2020.

Constitución Política de los Estados Unidos Mexicanos, 1917 (2020).

Declaración Universal de los Derechos Humanos, 10 de septiembre de 1948, Asamblea General de Naciones Unidas.

Observaciones finales a los informes periódicos quinto y sexto combinados de México. 28 Sesión del Comité de Derechos Económicos, Sociales y Culturales de la ONU, 29 de marzo de 2018.

Asamblea General de Naciones Unidas (1966). Pacto Internacional de Derechos Económicos, Sociales y Culturales.

Principio 14 del Pilar Europeo de Derechos Sociales, Cumbre social en favor del empleo justo y el crecimiento, Gotemburgo, noviembre de 2017. Real Decreto-ley 20/2020, del 29 de mayo, por el que se establece el ingreso mínimo vital, España. 
Esta revista forma parte del acervo de la Biblioteca Jurídica Virtual del Instituto de Investigaciones Jurídicas de la UNAM

Resolución del Parlamento Europeo del 24 de octubre de 2017, sobre las políticas encaminadas a garantizar la renta mínima como instrumento para luchar contra la pobreza.

Otros

Declaración del Relator Especial de las Naciones Unidas sobre la extrema pobreza y los derechos humanos, Philip Alston, sobre la conclusión de su visita oficial a España, 27 de enero-7 de febrero de 2020.

CEPAL. Estudio Económico de América Latina y el Caribe 2020: principales condicionantes de las políticas fiscal y monetaria en la era pospandemia de COVID-19. 